Arq. Bras. Med. Vet. Zootec., v.65, n.3, p.865-873, 2013

\title{
Avaliação nutricional de fenos produzidos com Andropogon gayanus cv. Planaltina
}

\author{
[Nutritional evaluation of hay produced with Andropogon gayanus cv. Planaltina] \\ G.R. Moreira ${ }^{1}$, E.O.S. Saliba ${ }^{2}$, L.C. Gonçalves ${ }^{2}$, R.M. Maurício ${ }^{3}$, L.F. Sousa ${ }^{4}$, \\ N.M. Rodriguez ${ }^{2}$, A.M.Q. Lana ${ }^{2}$

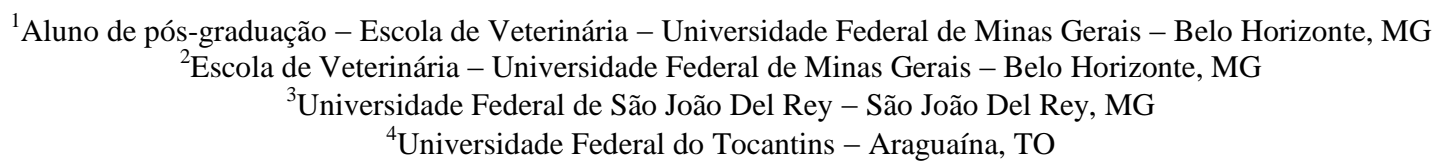

\section{RESUMO}

Neste estudo, foram utilizados fenos de Andropogon gayanus cv. Planaltina produzidos em diferentes idades de crescimento (56, 84, 112 e 140 dias) para ensaio de degradabilidade in vitro da matéria seca (DEIVMS), por meio da técnica in vitro semi-automática de produção de gases. Os dados de DEIVMS foram utilizados para confecção de equações que foram comparadas pelos testes de paralelismo e identidade de curvas. $\mathrm{O}$ teste de paralelismo não demonstrou diferença entre as equações e curvas, ou seja, as diferentes idades apresentaram o mesmo comportamento cinético de degradação. Contudo, pelo teste de identidade de curvas, observou-se que as equações e curvas dos fenos de A. gayanus colhidos com as plantas cortadas aos 56 e 84 dias são idênticas entre si, mas diferentes das demais, ou seja, apresentaram maior DEIVMS. Os fenos de A. gayanus nutricionalmente superiores são obtidos de plantas cortadas nos intervalos de 56 a 84 dias.

Palavras-chave: cinética ruminal, degradabilidade, forragem conservada

\begin{abstract}
In this study Andropogon gayanus cv. Planaltina hay produced at different ages of growth (56, 84, 112 and 140 days) were used for degradability assay of in vitro dry matter using semi-automated in vitro gas production technique. The data of in vitro dry matter degradation was used for the fabrication of equations and used for parallelism and curve identification comparison tests. The comparison between the A. gayanus hays harvested at different ages of growth by parallelism test showed that degradability in vitro dry matter curves are parallel. The similar curves showed kinetic behavior for in vitro dry matter degradability. When compared, the A. gayanus hays harvested at different ages of growth through the curve identification test, showed that A. gayanus hays harvested between 56 and 84 days are similar and had higher in vitro dry matter degradability. Nutritionally superior A. gayanus hay cut plants are obtained at intervals of 56 to 84 days.
\end{abstract}

Keywords: conservation forage, degradability, kinetics rumen

\section{INTRODUÇÃO}

O cultivar Planaltina de Andropogon gayanus Kunt var. biquamulatus foi introduzido no Brasil pelo Centro de Pesquisa Agropecuário do Cerrado (Embrapa-CPAC) (Thomas et al., 1981; Pizarro, 1984). Uma de suas características é concentrar a maior parte de sua produção de matéria seca durante a estação quente e chuvosa do ano (Pedreira e Matos, 1981). Para aproveitar esse potencial, a fenação constitui uma das alternativas recomendáveis.

A qualidade do feno, entretanto, está associada tanto a fatores relacionados às plantas, tais como: espécie e idade, quanto ao processo de produção:

Recebido em 10 de maio de 2011

Aceito em 25 de março de 2013

E-mail: guirocham@click21.com.br 
manejo do corte, que visa à desidratação adequada. As condições climáticas durante a secagem e o sistema de armazenamento empregado são fatores que interferem diretamente na qualidade bromatológica, bem como nas perdas no processo de produção (Reis et al., 2001).

Ensaios in vivo envolvendo produção animal e digestibilidade são os métodos mais adequados para se determinar o valor nutricional dos alimentos utilizados na nutrição dos ruminantes. Todavia, tais métodos requerem considerável uso de animais, alimentos, mão de obra, tempo e alto custo financeiro, limitando, assim, a sua aplicabilidade. Como consequência, várias técnicas in vitro vêm sendo utilizadas como opção, devido ao baixo custo e à rápida execução (Maurício et al., 2003a).

As técnicas in vitro de produção de gases são capazes de simular o ambiente ruminal e a digestão enzimática (Theodorou et al., 1994), apresentam comprovado potencial em descrever a cinética da fermentação no rúmen e estimar o consumo (Blümmel e Ørskov, 1993), em fornecer a taxa e a extensão da degradação das forrageiras (Getachew et al., 1998), bem como a medição dos produtos da fermentação de partes solúveis e insolúveis dos substratos (Pell e Schofield, 1993). Essas técnicas permitem avaliar grande número de substratos por experimento, apresentando alta acurácia nas medições, simplicidade no manuseio de equipamentos e baixo custo na implantação e por amostra analisada (Maurício et al., 1999).

Dessa forma, as técnicas in vitro de produção de gases têm se tornado opções para estudos de forrageiras para alimentação animal (Sousa et al., 2007; Guimarães Júnior et al., 2008; Castro et al., 2010).
O objetivo deste ensaio foi avaliar os fenos produzidos com Andropogon gayanus colhidos em diferentes idades, por meio da técnica in vitro semiautomática de produção de gases.

\section{MATERIAL E MÉTODOS}

O experimento foi realizado em fazenda localizada no município de Lagoa Santa, Minas Gerais, bioma Cerrado. Foi utilizada uma área preestabelecida de capim Andropogon gayanus cv. Planaltina. $\mathrm{Na}$ análise de solo, observaram-se as seguintes características: pH 5,3; alumínio $\left(\mathrm{Al}^{3+}\right) \quad 0,6 \quad \mathrm{cmol}$. carga/ $/ \mathrm{dm}^{3}$; fósforo $(\mathrm{P})$ $1,5 \mathrm{mg} / \mathrm{dm}^{3}$; potássio $(\mathrm{K}) 183 \mathrm{mg} / \mathrm{dm}^{3}$; índice de saturação de bases de $39 \%$ e classificação de textura denominada franco argilosa. Com base nas respostas obtidas por meio de análise do solo, procedeu-se à correção da acidez no início do período chuvoso, sendo aplicados $2000 \mathrm{~kg} / \mathrm{ha}$ de calcário dolomítico. Após 30 dias, foi realizada uniformização da área experimental, com utilização de roçadeira a $20 \mathrm{~cm}$ acima do solo e adubação. Para adubação de cobertura, foram utilizados $250 \mathrm{~kg} / \mathrm{ha}$ de 08-24-12 e $100 \mathrm{~kg} / \mathrm{ha}$ de $30-00-20$ (N:P:K). Foram demarcados 20 canteiros com $64 \mathrm{~m}^{2}(8 \times 8 \mathrm{~m})$ cada. A gramínea foi submetida ao corte em diferentes idades de crescimento: 56, 84, 112 e 140 dias, com cinco canteiros (repetições) por idade. O ensaio foi conduzido segundo o delineamento em blocos ao acaso, sendo os tratamentos as idades de corte que foram utilizadas para confecção dos fenos e os blocos os canteiros.

O primeiro corte foi realizado no dia 27 de janeiro de 2007, e os demais em intervalos de 28 dias. Os dados climáticos do período de dezembro de 2006 a abril de 2007 estão apresentados na Tab. 1.

Tabela 1. Dados climáticos do experimento durante o período de dezembro de 2006 a abril de 2007

\begin{tabular}{lccccc}
\hline \multirow{2}{*}{ Mês } & $\begin{array}{c}\text { Índice } \\
\text { pluviométrico } \\
(\mathrm{mm})\end{array}$ & Mínima & Máxima & Média & $\begin{array}{c}\text { Umidade relativa do } \\
\text { ar }(\%)\end{array}$ \\
\cline { 3 - 5 } & 304,4 & 19 & 38 & 28,5 & 53,59 \\
Dezembro de 2006 & 230,7 & 20 & 39 & 29,5 & 51,88 \\
Janeiro de 2007 & 134,1 & 22 & 38 & 30,0 & 50,17 \\
Fevereiro de 2007 & 51,8 & 15 & 39 & 27,0 & 46,79 \\
Março de 2007 & 55,0 & 16 & 37 & 26,5 & 53,96 \\
Abril de 2007 & & & & & \\
\hline
\end{tabular}


Nas idades determinadas, o capim A. gayanus foi cortado a $20 \mathrm{~cm}$ acima do nível do solo utilizando-se roçadeira costal. Em cada idade, foram colhidas forragens dos cinco canteiros. Uma bordadura de $2 \mathrm{~m}$ de cada lado dos canteiros foi desprezada para evitar efeitos externos, sendo a área útil com dimensões de $36 \mathrm{~m}^{2}$ (6x6m) por canteiro. Uma fração dessa área foi retirada e utilizada para produção dos fenos.

A confecção dos fenos foi realizada colocando-se a forragem cortada anteriormente em bandejas de ferro de $1 \mathrm{~m}^{2}(1 \mathrm{x} 1 \mathrm{~m})$, em camadas de $5 \mathrm{~cm}$, as quais foram expostas ao sol, sendo reviradas quatro vezes por dia. Caso não dessem ponto de feno, as bandejas eram recolhidas e colocadas em galpão, para evitar o orvalho, e no dia seguinte eram expostas novamente ao sol. O ponto de feno era observado quando, ao torcer um molho de folhas e hastes, apenas algumas se rompiam.

Posteriormente, os fenos foram secos em estufa a $55^{\circ} \mathrm{C}$ por 72 horas e processados em moinho com peneira de crivos de $1 \mathrm{~mm}$.

$\mathrm{Na}$ fase laboratorial, foram determinados os valores de matéria pré-seca (MS) e proteína bruta (PB) de acordo com Official... (1995); de fibra em detergente neutro (FDN), fibra em detergente ácido (FDA) e lignina segundo Van Soest et al. (1991) (Tab. 2).

Tabela 2. Teores de matéria seca (MS), proteína bruta (PB), fibra em detergente neutro (FDN), fibra em detergente ácido (FDA) e lignina (LIG) de fenos produzidos em diferentes idades de crescimento do Andropogon gayanus cv. Planaltina

\begin{tabular}{|c|c|c|c|c|}
\hline \multirow[b]{2}{*}{ Nutriente $(\%)$} & \multicolumn{4}{|c|}{ Idade de corte } \\
\hline & 56 & 84 & 112 & 140 \\
\hline $\mathrm{MS}^{*}$ & 91,4 & 91,5 & 92,2 & 92,4 \\
\hline $\mathrm{PB}^{*}$ & 8,6 & 6,5 & 4,9 & 3,8 \\
\hline $\mathrm{FDN}^{*}$ & 73,8 & 75,4 & 76,7 & 79,3 \\
\hline FDA $^{*}$ & 38,3 & 39,9 & 40,8 & 42,9 \\
\hline $\mathrm{LIG}^{*}$ & 4,5 & 4,6 & 5,3 & 6,7 \\
\hline
\end{tabular}

Valores na base seca.

Foi realizada estimativa de equação de regressão para as variáveis MS, PB, FDN e FDA em função da idade de corte.

$\mathrm{O}$ experimento com a utilização da técnica in vitro semiautomatica de produção de gases foi realizado segundo o delineamento estatístico em blocos ao acaso, com arranjo em parcelas subdivididas, sendo que as idades de corte do $A$. gayanus que foram utilizadas para confecção dos fenos constituíram as parcelas, e os tempos de degradação (seis, 12, 24, 48 e 96 horas) e cinética de fermentação ruminal (quatro, seis, oito, $10,12,16,19,24,30,36,48,72$ e 96 horas) formaram as subparcelas, com cinco repetições por tratamento (blocos), já descritos anteriormente.

Os fenos foram processados em moinho com peneira dotada de crivo de $1 \mathrm{~mm}$. Em seguida, pesou-se $1 \mathrm{~g}$ de cada amostra, que foi adicionado ao frasco de fermentação com capacidade de $160 \mathrm{~mL}$, onde previamente fora injetado gás carbônico $\left(\mathrm{CO}_{2}\right)$. Posteriormente, foram adicionados $90 \mathrm{~mL}$ de meio de cultura segundo
Theodorou et al. (1994). Os frascos foram vedados com rolha de silicone e levados para geladeira com temperatura de $4^{\circ} \mathrm{C}$, onde permaneceram durante oito horas. Depois, foram colocados em estufa a $39^{\circ} \mathrm{C}$ e ali permaneceram até a inoculação.

O inóculo ruminal foi obtido e colhido de bovino macho da raça Jersey fistulado no rúmen, antes do fornecimento da alimentação matinal. A dieta do animal foi calculada para atender as exigências de mantença e peso constante, tendo como volumoso o feno de tifton-85 (Cynodon spp.) suplementado com concentrado comercial com $18 \%$ de proteína bruta (PB).

Os frascos contidos na estufa foram retirados e inoculados com $10 \mathrm{~mL}$ de líquido ruminal por frasco. Após a inoculação, os frascos foram vedados com rolha de silicone, e os gases residuais presentes (tempo zero) foram eliminados com o auxílio de agulhas. Os frascos foram novamente mantidos na estufa a $39^{\circ} \mathrm{C}$. 
Frascos sem substratos (amostras de forrageiras), denominados brancos, contendo apenas inóculo e meio de cultura, foram incubados para correção dos gases e desconto de eventuais contaminações provenientes da fermentação do inóculo.

As leituras de pressão foram realizadas em intervalos de duas, quatro, seis, oito, 10, 12, 16, 19, 24, 30, 36, 48, 72 e 96 horas, com a inserção de uma agulha fixada ao transdutor de pressão.

As leituras de pressão realizadas foram transformadas em volume de gases pela equação definida por Maurício et al. (2003b), descrita abaixo:

$\mathrm{V}=\left(0,051 \times \mathrm{P}^{2}\right)+(4,43 \times \mathrm{P})-(0,004)$, em que:

$\mathrm{V}=$ volume de gases $(\mathrm{mL})$;

$\mathrm{P}=$ pressão em polegada por $\mathrm{cm}^{2}$.

Os frascos referentes aos tempos seis, 12, 24, 48, 96 horas e seus respectivos brancos foram retirados da estufa e resfriados com água fria para interromper a fermentação, em seguida armazenados sob refrigeração a $4^{\circ} \mathrm{C}$, até a realização do processo de filtragem. A degradabilidade in vitro da matéria seca (DEIVMS) em cada tempo foi obtida pela filtragem do conteúdo dos frascos sob vácuo, em cadinhos de filtragem de borossilicato, porosidade 1 , revestidos internamente com de lã de vidro. Os cadinhos foram previamente pesados. O resíduo de incubação foi mantido por 24 horas em estufa a $105^{\circ} \mathrm{C}$ e pesado.

Com base nos dados de degradação, confeccionaram-se equações de regressão que foram comparadas pelos testes de paralelismo e identidade de curvas descritos por Freese (1970) a $5 \%$ de probabilidade do erro.

Os volumes acumulados de gases foram utilizados para o cálculo de equações segundo France et al. (1993):

$\mathrm{Y}=\mathrm{A} \times\left\{1-\exp ^{[-\mathrm{b}(\mathrm{t}-\mathrm{L})-\mathrm{c} \times(\sqrt{ } \mathrm{t}-\sqrt{ } \mathrm{L})]}\right\}$, em que:

$\mathrm{Y}=$ produção acumulativa de gases $(\mathrm{mL})$;

$\mathrm{A}=$ máxima produção acumulada de gases $(\mathrm{mL})$;

$\mathrm{L}=$ tempo de colonização $(\mathrm{h})$;

$b\left(\mathrm{~h}^{-1}\right)$ e $c\left(\mathrm{~h}^{-0,5}\right)=$ taxas fracionais constantes; $\mathrm{t}=$ tempo (horas).
Equações oriundas dessas análises de regressão foram comparadas pelos testes de paralelismo e identidade de curvas descritos por Freese (1970) a $5 \%$ de probabilidade do erro.

A taxa fracional média $\left(\mathrm{h}^{-1}\right)$ de produção de gases $(\mu)$ foi calculada como:

$\mu=\underline{b+c}$,

$2 \sqrt{ } t$

em que:

$\mu=$ taxa de produção de gases $\left(\mathrm{h}^{-1}\right)$;

os demais termos foram definidos anteriormente.

Os dados de degradabilidade efetiva (DE) foram estimados por meio dos dados de produção de gases e degradabilidade in vitro com 96 horas de incubação, utilizando-se o software Maximum Likelihood Program (MLP) segundo Ross (1980). A taxa de passagem para o cálculo da DE foi $\mathrm{k}=0,02$; sendo esta indicada para alimentos volumosos (Ørskov et al., 1980).

A correlação de Pearson foi empregada para avaliação das associações entre DE e o teor de LIG.

\section{RESULTADOS E DISCUSSÃO}

Nas Fig. 1, 2, 3, 4 e 5, podem-se observar as equações de regressão da composição bromatológica (valores na base seca) dos fenos produzidos em diferentes idades $(56,84,112 \mathrm{e}$ 140 dias) de crescimento do Andropogon gayanus cv. Planaltina.

Os teores de matéria seca (MS) foram elevados linearmente com o avançar do estádio de maturidade da forrageira (Fig. 1), sendo que o valor mínimo foi observado para o feno da forragem cortada aos 56 dias com 91,3\% de MS e o valor máximo foi observado para o feno da planta colhida aos 140 dias, com valor de 92,3\% de MS. Segundo Ataíde Júnior et al. (2000), fenos são produzidos de forragens verdes desidratadas com umidade inferior a $15 \%$, o que permite que sejam armazenados, desde que adequadamente, sem deterioração de seus princípios nutritivos. Portanto, os fenos avaliados nesta pesquisa apresentaram teores adequados de MS e puderam ser armazenados sem que houvesse perda de seus valores nutritivos. 


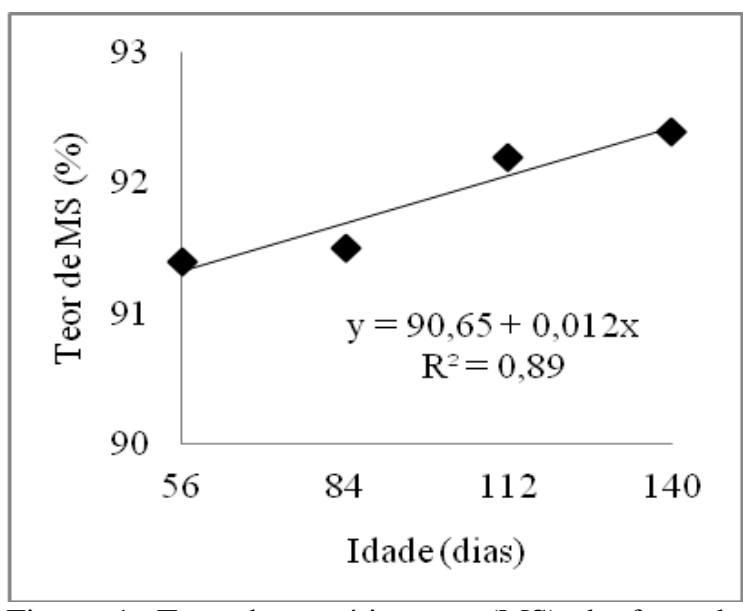

Figura 1. Teor de matéria seca (MS) do feno de Andropogon gayanus cv. Planaltina ao longo dos dias.

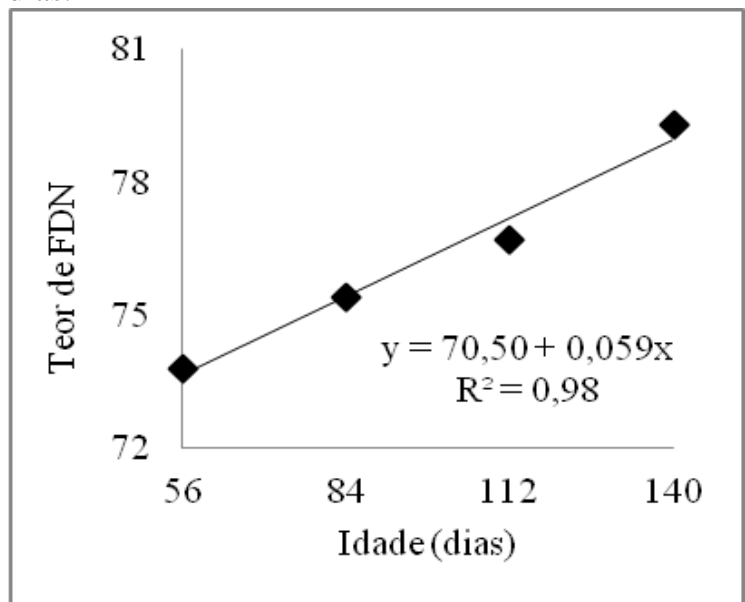

Figura 3. Teor de fibra em detergente neutro (FDN) do feno de Andropogon gayanus cv. Planaltina ao longo dos dias.

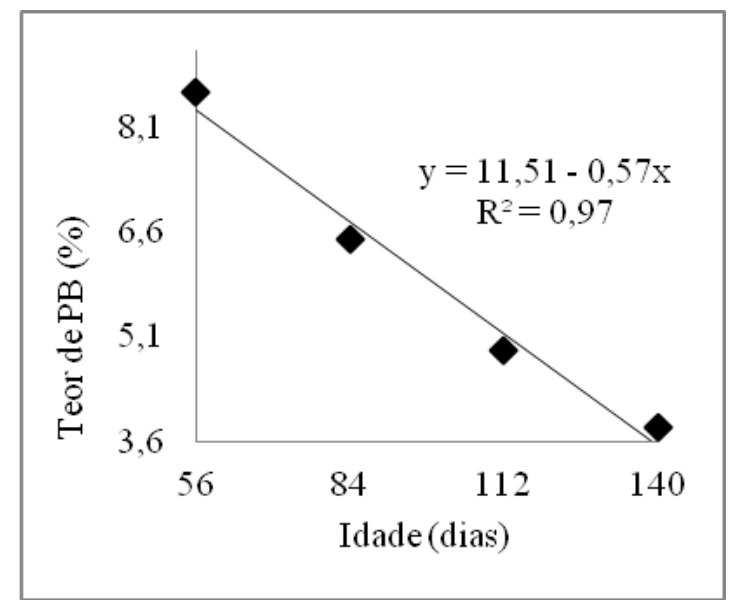

Figura 2. Teor de proteína bruta (PB) do feno de Andropogon gayanus cv. Planaltina ao longo dos dias.

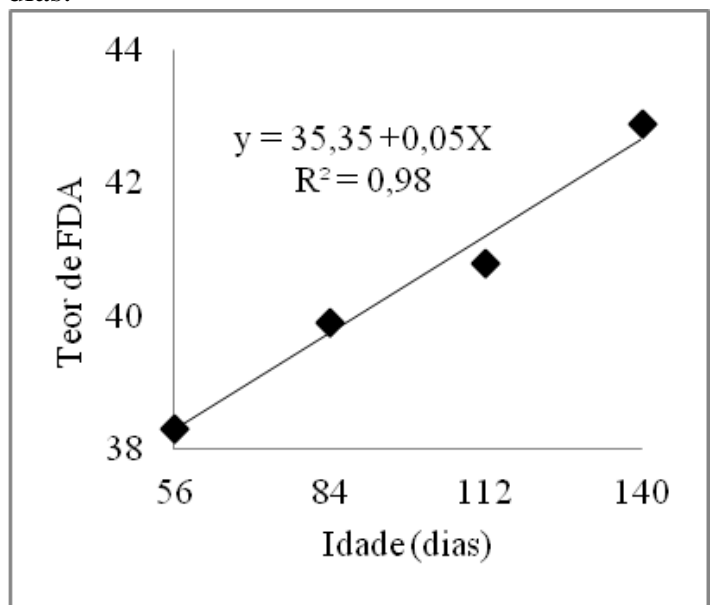

Figura 4. Teor de fibra em detergente ácido (FDA) do feno de Andropogon gayanus cv. Planaltina ao longo dos dias.

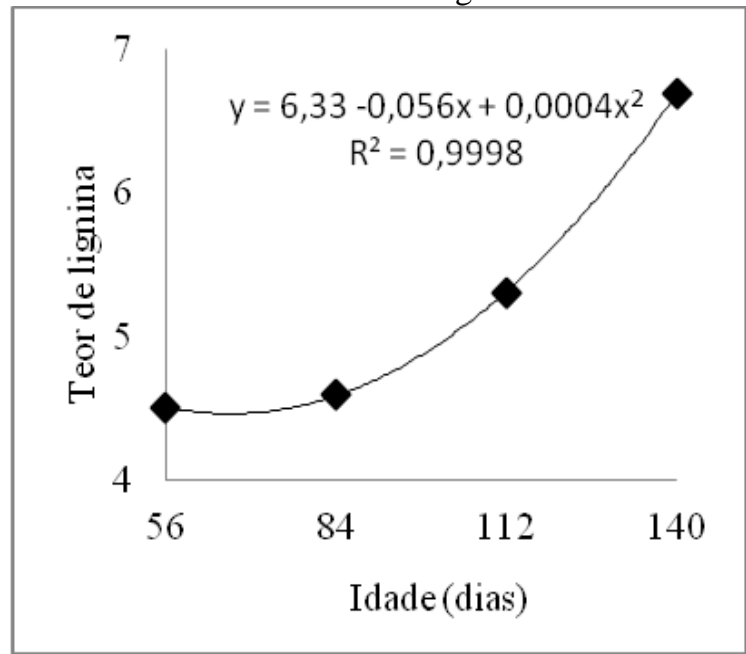

Figura 5. Teor de lignina do feno de Andropogon gayanus cv. Planaltina ao longo dos dias. 
Com o avançar do estádio de maturidade da forrageira, foi observada diminuição linear do teor de proteína bruta (PB) nos fenos produzidos (Fig. 2). Observou-se por essa equação que somente os fenos das plantas cortadas nos intervalos de 56 a 96 dias apresentaram concentrações superiores a 6\%, valor que, segundo Van Soest (1994), é a concentração mínima para manutenção adequada da microbiota ruminal. Esses resultados corroboram os de Rodrigues et al. (2004), os quais, ao trabalharem com a gramínea $A$. gayanus cv. Planaltina cortada aos 21, 42 e 63 dias, observaram diminuição do teor de PB ao longo do tempo, com valores de 11,86; 7,88 e $6,92 \%$, respectivamente.

A fibra em detergente neutro (FDN) e a fibra em detergente ácido (FDA) aumentaram linearmente com a idade de corte do Andropogon para confecção dos fenos (Fig. 3 e 4). Como a FDN, segundo Jung e Allen (1995), está relacionada ao consumo voluntário e a FDA está relacionada a alterações na digestibilidade (Van Soest, 1994), provavelmente os fenos do A. gayanus colhidos nas idades mais avançadas serão menos consumidos e degradados.

Os teores de FDN observados na equação de regressão para as idades de 56,84 e 112 dias $(73,8 ; 75,45$ e $77,11 \%$, respectivamente) foram numericamente próximos aos observados por Barbi (1991), que, ao trabalhar com o capim Andropogon nessas mesmas idades, encontrou valores de 72,9; 74,3 e 73,9\%, respectivamente.

Esses resultados para os teores de FDA no feno do capim Andropogon cortado aos 56, 84 e 112 dias, obtidos pela equação de regressão $(38,2$; 39,6 e $41,0 \%$, respectivamente), foram inferiores aos observados por Barbi (1991), que obteve teores de FDA de 42,4; 44,9 e 44,6\%, respectivamente, para essas idades.
A concentração de lignina (LIG) aumentou quadraticamente nos fenos produzidos com $A$. gayanus com o avançar da idade de colheita (Fig. 5), sendo o menor valor observado aos 70 dias $(4,37 \%)$. Como a LIG afeta a digestibilidade dos componentes da parede celular e esse efeito é mais pronunciado com o avançar da idade das forragens (Wilson e Hatfield, 1997), provavelmente os fenos produzidos com a forragem colhida nos estádios mais avançados serão menos degradados.

Os teores de LIG encontrados na equação de regressão aos 56 e 112 dias foram superiores àqueles observados por Barbi (1991), que encontrou 3,6 e 4,5\% para essas respectivas idades. Entretanto, o feno do capim Andropogon produzido aos 84 dias de crescimento foi numericamente igual ao avaliado por Barbi (1991) na mesma idade, o qual encontrou $4,4 \%$ de LIG.

$\mathrm{Na}$ Tab. 3 e na Fig. 1, estão expressas as equações e curvas de regressão da degradabilidade in vitro da matéria seca (DEIVMS) nos fenos de Andropogon gayanus cv. Planaltina colhidos em diferentes idades de crescimento.

O teste de paralelismo de curvas não demonstrou diferença $(\mathrm{P}>0,05)$ entre as equações e curvas de DEIVMS para o feno de Andropogon produzido de plantas colhidas em diferentes idades, ou seja, as diferentes idades apresentaram o mesmo comportamento cinético de DEIVMS.

No teste de identidade de curvas, entretanto, observou-se que as equações e curvas dos fenos do Andropogon gayanus cv. Planaltina colhidos com as plantas cortadas aos 56 e 84 dias são idênticas entre si, mas diferentes das demais, ou seja, apresentam maior $(\mathrm{p}<0,05)$ DEIVMS.

Tabela 3. Equações de regressão da degradabilidade in vitro da matéria seca (MS) do feno de Andropogon gayanus cv. Planaltina produzido em diferentes idades de crescimento

\begin{tabular}{lclc}
\hline Variável & Idade & Equações & $\mathrm{R}^{2}$ \\
\hline \multirow{3}{*}{ MS } & 56 & $\mathrm{Y}=2,27+1,64 \mathrm{~T}-0,01 \mathrm{~T}^{2} \mathrm{aA}$ & 0,99 \\
& 84 & $\mathrm{Y}=2,95+1,59 \mathrm{~T}-0,01 \mathrm{~T}^{2} \mathrm{aA}$ & 0,99 \\
& 112 & $\mathrm{Y}=4,18+1,39 \mathrm{~T}-0,01 \mathrm{~T}^{2} \mathrm{aB}$ & 0,99 \\
& 140 & $\mathrm{Y}=2,45+1,11 \mathrm{~T}-0,01 \mathrm{~T}^{2} \mathrm{aC}$ & 0,99 \\
\hline
\end{tabular}

Equações acompanhadas por letras minúsculas e maiúsculas iguais na coluna são paralelas e idênticas, respectivamente, segundo Freese (1970), a 5\% de probabilidade do erro. 


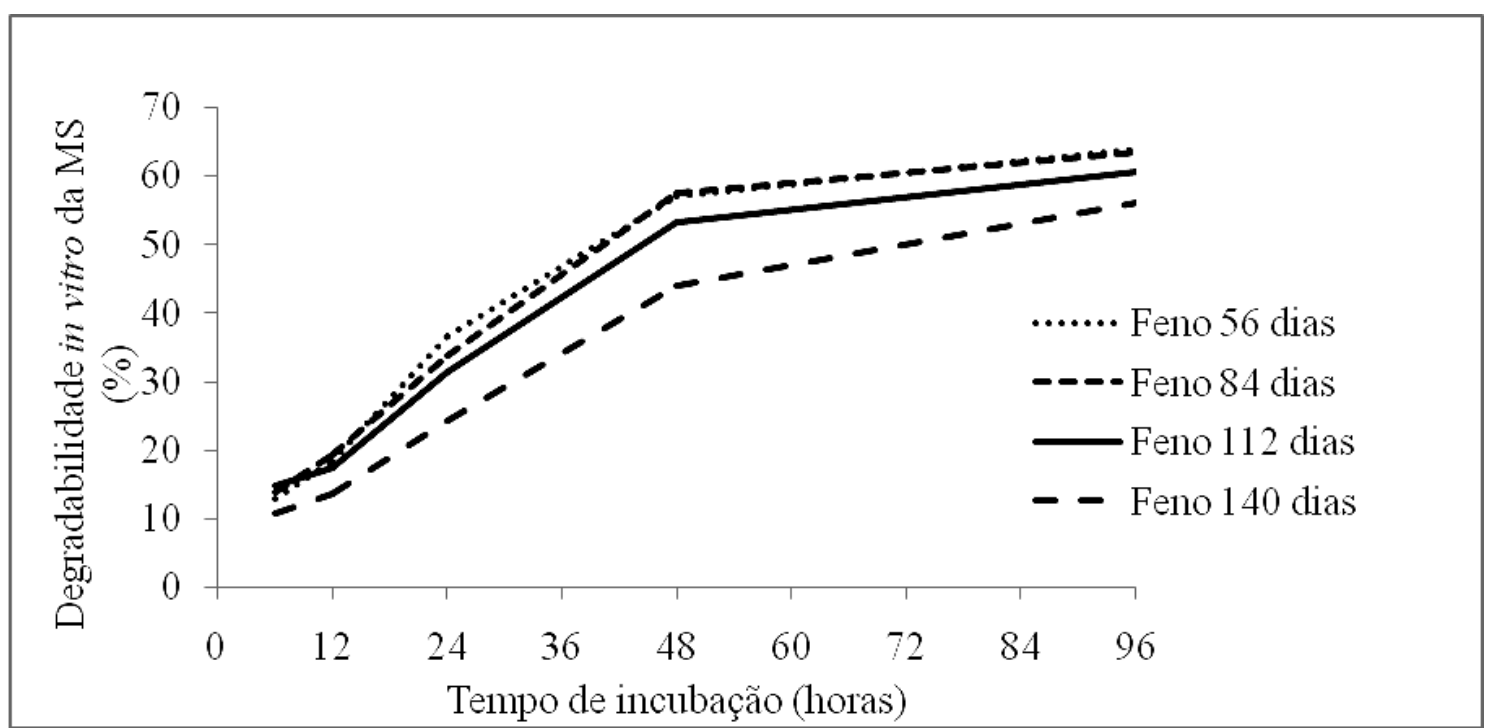

Figura 5. Degradabilidade in vitro da matéria seca (MS) do feno de Andropogon gayanus cv. Planaltina produzido em diferentes idades de crescimento.

$\mathrm{Na}$ Tab. 4 e na Fig. 2, estão expressas as equações e curvas geradas pelas análises de fenos de A. gayanus colhidos em diferentes regressão ao modelo de France et al. (1993) nos

Tabela 4. Equações geradas pelas análises de regressão ao modelo de France et al. (1993) nos fenos de $A$. gayanus colhidos em diferentes idades de crescimento

\begin{tabular}{|c|c|c|}
\hline Idade & Equações & $\mathrm{R}^{2}$ \\
\hline 56 & $\mathrm{Y}=229,72 \times\left\{1-\exp ^{[-(0,0611) \times(\mathrm{t}-4,61)-(-0,2625) \times(\sqrt{ } \mathrm{t}-\sqrt{ } 4,61)]}\right\}$ a $\mathrm{A}$ & 0,99 \\
\hline 84 & $Y=228,62 \times\left\{1-\exp ^{[-(0,0543) \times(t-3,38)-(-0,2100) \times(\sqrt{ } t-\sqrt{ } 3,38)]}\right\}$ a $A$ & 0,99 \\
\hline 112 & $Y=221,29 \times\left\{1-\exp ^{[-(0,0552) \times(t-4,04)-(-0,2219) \times(\vee t-V 4,04)]}\right\}$ a B & 0,99 \\
\hline 140 & $Y=213,07 \times\left\{1-\exp ^{[-(0,0457) \times(t-4,66)-(-0,1977) \times(\vee t-\vee 4,66)]}\right\}$ a $C$ & 0,99 \\
\hline
\end{tabular}

Equações acompanhadas por letras minúsculas e maiúsculas iguais na coluna são paralelas e idênticas, respectivamente, segundo Freese (1970), a 5\% de probabilidade do erro.

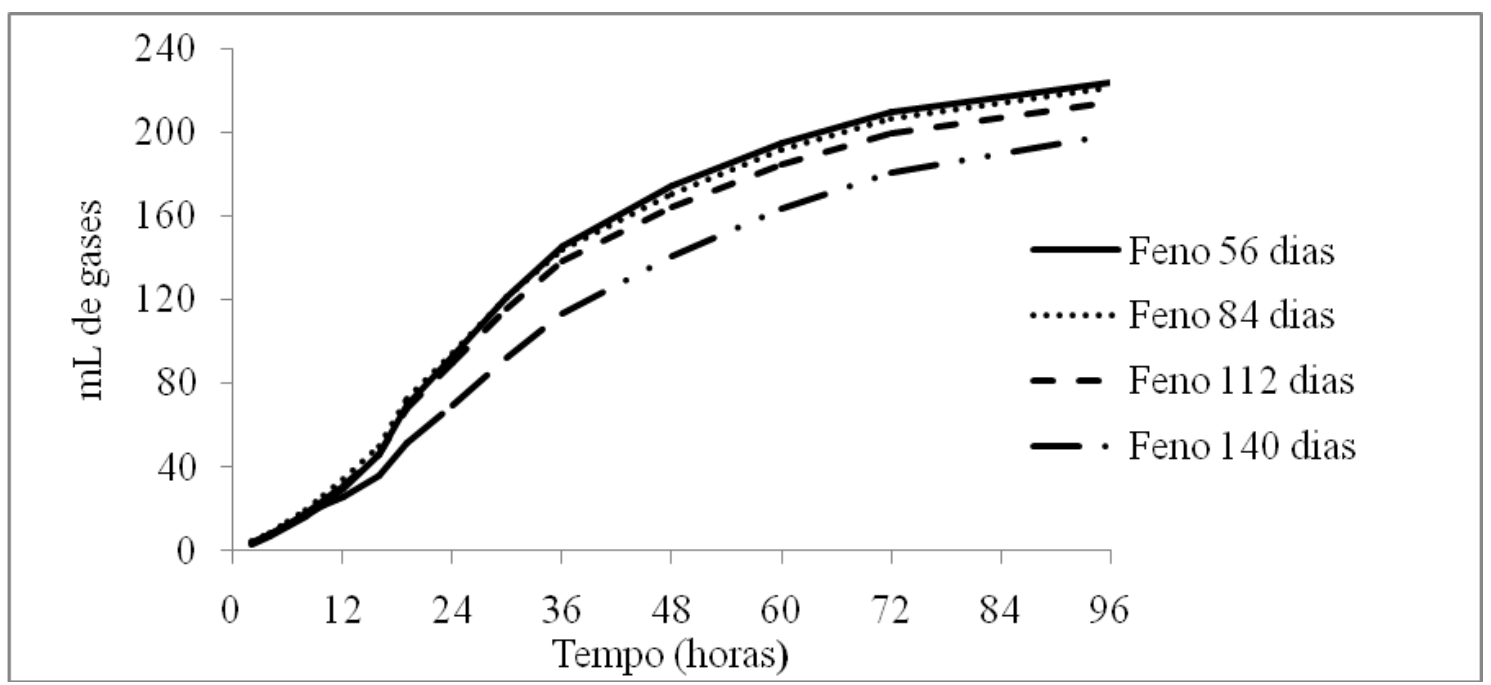

Figura 6. Produção acumulada de gases (mL) nos fenos de A. gayanus colhidos em diferentes idades de crescimento, obtidos pelas análises de regressão ao modelo de France et al. (1993). 
A comparação entre os fenos do A. gayanus colhidos em diferentes idades de crescimento pelo teste de paralelismo demonstrou que as curvas de produção acumulada de gases são paralelas $(p>0,05)$, ou seja, as curvas apresentaram o mesmo comportamento cinético de fermentação ruminal.

Contudo, quando foram comparados os fenos do A. gayanus colhidos em diferentes idades de crescimento $(56,84,112$ e 140 dias) pelo teste de identidade de curvas, observou-se que os fenos do A. gayanus colhidos com as plantas cortadas aos 56 e 84 dias são idênticos, produziram maior quantidade de gases por unidade de matéria orgânica fermentada, ou seja, essas idades foram mais degradadas.

Na Tab. 5, são observadas a taxa de produção de gases $(\mu)$ e a degradabilidade efetiva (DE) dos fenos de Andropogon gayanus cv. Planaltina produzidos em diferentes idades de crescimento.

Tabela 5. Taxa de produção de gases $(\mu)$ e degradabilidade efetiva (DE) dos fenos de Andropogon gayanus cv. Planaltina produzidos em diferentes idades de crescimento

\begin{tabular}{|c|c|c|c|c|}
\hline \multirow{2}{*}{ Parâmetros } & \multicolumn{4}{|c|}{ Idade de corte } \\
\hline & 56 & 84 & 112 & 140 \\
\hline$\mu$ (/hora-1) & 0,035 & 0,034 & 0,034 & 0,025 \\
\hline $\mathrm{DE}(2 \%)$ & 58,4 & 58,8 & 55,4 & 56,4 \\
\hline
\end{tabular}

A taxa de produção de gases $(\mu)$ foi próxima nos fenos do A. gayanus colhidos aos 56, 84 e 112 dias. Os resultados observados neste estudo com relação à $\mu$ confirmam observações feitas anteriormente por Castro et al. (2007), que observaram diminuição na $\mu$ com o avanço da idade de corte da Brachiaria brizantha cv. Marandu.

A degradabilidade efetiva (DE) foi semelhante nos fenos do A. gayanus colhidos aos 56 e 84 dias de idade, intermediária aos 112 e inferior no feno do A. gayanus colhido aos 140 dias. Provavelmente as maiores DE observadas para os fenos da forragem colhidos aos 56 e 84 estão relacionadas à correlação observada (Tab. 6) entre a DE e o teor de LIG, pois, segundo Jung e Allen (1995), a composição e a concentração de LIG podem afetar a taxa de degradação. Como o teor de lignina aumentou com a idade de colheita do A. gayanus (equação de regressão da Tab. 2) e a correlação entre DE e LIG é negativa ( $\mathrm{r}=$ $0,90)$, o aumento do teor de lignina diminuiu a DE.

\section{CONCLUSÃO}

Os fenos de A. gayanus nutricionalmente superiores são obtidos de plantas cortadas nos intervalos de 56 a 84 dias.

\section{REFERÊNCIAS}

ATAIIDE JÚNIOR, J.R; PEREIRA, O.G.; GARCIA, R. et al. Valor nutritivo do feno de capim Tifton-85 (Cynodon spp.) em diferentes idades de rebrota, em ovinos. R. Bras. Zootec., v.29, p.2193-2199, 2000. (suplemento 2).

BARBI, J.H.T. Avaliação da degradabilidade ruminal de quatro gramíneas tropicais em diferentes idades de corte pela técnica in situ. 1991. 67f. Dissertação (Mestrado em Zootecnia) - Escola de Veterinária Universidade Federal de Minas Gerais, Belo Horizonte

BLÜMMEL, M.; ØRSKOV, E.R. Comparison of in vitro gas production and naylon degradability of roughage in predicting feed intake in cattle. Anim. Feed Sci. Technol., v.40, p.109-119, 1993.

CASTRO, G.H.F.; GRAÇA, D.S.; GONÇALVES, L.C. et al. Cinética de degradação e fermentação ruminal da Brachiaria brizantha cv. Marandu colhida em diferentes idades ao corte Arq. Bras. Med. Vet. Zootec., v.59, p.1538-1544, 2007.

CASTRO, G.H.F.; RODRIGUEZ, N.M.; GONÇALVES, L.C. et al. Características produtivas, agronômicas e nutricionais do capim-tanzânia em cinco diferentes idades ao corte. Arq. Bras. Med. Vet. Zootec., v.62, p.654-666, 2010.

FRANCE, J.; DHANOA, M.S.; THEODOROU, M.K. et al. A model to interpret gas accumulation profiles with in vitro degradation of runinant feeds. J. Theor. Biol., v.163, p.99-111, 1993. 
FREESE, F. Métodos estatísticos elementares para tecnicos forestales. Buenos Aires - Argentina: Centro Regional de Ayuda tecnica; Agencia para el desarrollo internacional (AID), 1970. 105p. (Manual da Agricultura, 317).

GETACHEW, G.; BLÜMMEL, M.; MAKKAR, H.P.S. et al. In vitro gas measuring techniques for assessment of nutritional quality of feeds: a review. Anim. Feed Sci. Technol., v.72, p.261-281, 1998.

GUIMARÃES JÚNIOR, R.; GONÇALVES, L.C.; MAURÍCIO, R M. et al. Cinética de fermentação ruminal de silagens de milheto. Arq. Bras. Med. Vet. Zootec., v.60, p.1174-1180, 2008.

JUNG, H.G.; ALLEN, M.S. Characteristics of plant cell walls affecting intake and digestibility of forages by ruminants. J. Anim. Sci., v.73, p.2774-2790, 1995.

MAURÍCIO, R.M.; MOULD, F.; DHANOA, M.S. et al. A semi-automated in vitro gas production technique for ruminants feedstuff evaluation. Anim. Feed Sci. Technol., v.79, p.321-330, 1999.

MAURÍCIO, R.M.; PEREIRA, L.G.R.; GONÇALVES, L.C. et al. Potencial da técnica in vitro semi-automática de produção de gases para avaliação de silagens de sorgo (Sorghum bicolor (L.) Moench). R. Bras. Zootec., v.32, p.1013-1020, 2003 a.

MAURÍCIO, R.M.; PEREIRA, L.G.R.; GONÇALVES, L.C. et al. Relação entre pressão e volume para implantação da técnica in vitro semiautomática de produção de gases na avaliação de forrageiras tropicais. Arq. Bras. Med. Vet. Zootec., v.55, p.56-61, 2003b.

OFFICIAL Methods of Analysis of the AOAC International. v.1.16. ed. Virginia: AOAC, 1995.

ØRSKOV, E.R.; HOVELL, F.D.B.; MOULD, F. The use of the nylon bag technique for evaluation of feedstuffs. Trop. Anim. Produc., v.5, p.195-213. 1980.

PEDREIRA, J.V.S.; MATTOS, H.B. Crescimento estacional de vinte e cinco espécies ou variedades de capins. BIA, v.30, p.117-143, 1981.

PELL, A.N.; SCHOFIELD, P. Computerized monitoring of gas production to measure forage digestion in vitro. J. Dairy Sci., v.6, p.1063- 1073, 1993.
PIZARRO, E.A. Introduction. In: MEJIA, M.M. Andropogon gayanus Kunth: Bibliografia Analítica. Cali: CIAT, 1984. 196 p.

REIS, R.A.; MOREIRA, A.L.; PEDREIRA, M.S. Técnicas para produção e conservação de fenos de forrageiras de alta qualidade. In: SIMPÓSIO SOBRE PRODUÇÃO E UTILIZAÇÃO DE FORRAGENS CONSERVADAS, 2001, Maringá. Anais... Maringá: UEM/CCA/DZO, 2001. p.1-19.

RODRIGUES, A.L.P.; SAMPAIO, I.B.; CARNEIRO, J.C. et al. Degradabilidade in situ da matéria seca de forrageiras tropicais obtidas em diferentes épocas de corte. Arq. Bras. Med. Vet. Zootec., v.56, p.658-664, 2004.

ROSS, G.J.S. Maximum Likelihood Program (A Manual). Oxford - England: Numerical Algorithms Group Ltd. 1980. 130p.

SOUSA, L.F.; MAURÍCIO, R.M.; GONÇALVES, L.C. et al. Produtividade e valor nutritivo da Brachiaria brizantha cv. Marandu em um sistema silvipastoril. Arq. Bras. Med. Vet. Zootec., v.59, p.1029-1037, 2007.

THEODOROU, M.K.; WILLIANS, B.A.; DHANOA, M.S. et al. A simple gas production method using a pressure transducer to determine the fermentation kinetics of ruminant feeds. Anim. Feed Sci. Technol., v.48, p.185-197, 1994.

THOMAS, D.; ANDRADE, R.P.; COUTO, W. et al. Andropogon gayanus var. bisquamulatus cv. Planaltina: Principais características forrageiras. Pesq. Agrop. Bras., v.16, p.347-355, 1981.

VAN SOEST, P.J. Nutritional ecology of the ruminant. 2. ed. Ithaca: Cornell University Press, 1994. 476p.

VAN SOEST, P.J.; ROBERTSON, J.B.; LEWIS, B.A. Methods for dietary fiber, neutral detergent fiber and no starch polysaccharides in relation to animal nutrition. J. Dairy Sci., v.74, p.3583-3597, 1991.

WILSON, J.R.; HATFIELD, R.D. Structural and chemical changes of cell wall types during stem development: consequences for fibre degradation by rumen microflora. Austr. J. Agric. Res., v.48, p.165180, 1997. 